\title{
Rapid Detection of Avian Influenza Virus H5N1 in Chicken Tracheal Samples Using an Impedance Aptasensor with Gold Nanoparticles for Signal Amplification
}

Sardar Karash ${ }^{\mathrm{a}}$, Ronghui Wang ${ }^{\mathrm{b}}$, Lisa Kelso ${ }^{\mathrm{c}}$, Huaguang $\mathrm{Lu}^{\mathrm{d}}$, Tony Jun Huang ${ }^{\mathrm{e}}$, Yanbin $\mathrm{Li}^{\mathrm{a}, \mathrm{b}, \mathrm{c}, *}$

${ }^{a}$ Cell and Molecular Biology Program, ${ }^{b}$ Department of Biological and Agricultural Engineering,

${ }^{c}$ Center of Excellence for Poultry Science, University of Arkansas, Fayetteville, AR 72701

${ }^{d}$ Animal Diagnostic Laboratory, ${ }^{e}$ Department of Engineering Science and Mechanics \& Material Research Institute, Pennsylvania State University, State College, PA 16802, USA

\section{*Corresponding author:}

Yanbin Li, Department of Biological and Agricultural Engineering, University of Arkansas, 203 Engineering Hall, Fayetteville, AR 72701, USA.

Phone: (479) 575-2881; Fax: (479) 575-2846; Email: yanbinli@uark.edu 


\begin{abstract}
Highly pathogenic avian influenza virus $\mathrm{H} 5 \mathrm{~N} 1$ is a continuous threat to public health and poultry industry. The recurrence of the $\mathrm{H} 5 \mathrm{~N} 1$ led us to develop a robust, specific, and rapid detection method for the virus. In this study, an impedance aptasensor was developed for the virus detection using specific H5N1 aptamer and a gold interdigitated microelectrode. Streptavidin was immobilized on the microelectrode surface and biotin labeled H5N1 aptamer was bound to the immobilized streptavidin. The microelectrode was blocked with the polyethylene glycol and the bound aptamer captured the virus. The impedance change caused by the captured virus was measured using an impedance analyzer. To enhance impedance signal, a nanoparticle-based amplifier was designed and implemented by forming a network-like gold nanoparticles/H5N1aptamer/thiocyanuric acid. The detection limit of the impedance aptasensor was 0.25 HAU for the pure virus and $1 \mathrm{HAU}$ for the tracheal chicken swab samples spiked with the H5N1 virus. The detection time of aptasensor without employing the amplifier was less than an hour. The amplifier increased impedance by a 57-fold for the 1 HAU samples. Only negligible impedance change was observed for non-target viruses such as $\mathrm{H} 5 \mathrm{~N} 2, \mathrm{H} 5 \mathrm{~N} 3, \mathrm{H} 7 \mathrm{~N} 2, \mathrm{H} 1 \mathrm{~N} 1$, and $\mathrm{H} 2 \mathrm{~N} 2$. This aptasensor provides a foundation for the development of a portable aptasensor instrument.
\end{abstract}

Key words: Avian influenza H5N1, aptasensor, aptamer, amplifier, microelectrode 


\section{Introduction}

Avian Influenza A virus (AIV) is not only considered a zoonotic infection, but under certain conditions, the virus causes a serious public health threat. Highly pathogenic avian influenza A virus H5N1 (HPAI H5N1) poses a major challenge to human and avian. According to the official report of the World Health Organization (WHO, 2015), there were 844 laboratory-confirmed human cases with HPAI H5N1 infection since 2003 in 16 countries, of which 449 (case fatality rate (CFR) 53\%) died with the infection. According to Food and Agriculture Organization (2012), HPAI H5N1 has caused the killing or culling of more than 400 million domestic birds across the world. This cost up to $\$ 20$ billion in poultry industry. It has been impossible to fully eradicate the virus from chicken flocks, wild birds, and to prevent transmission to mammals. Therefore, the H5N1 is a persistent threat to humans and animals because the virus mutates and evolves. This gives it the ability to infect humans due to their lack of immunological defenses, and this will increase the chance of a potentially perilous pandemic (Webster et al., 1992; Guan et al., 2004; Fauci and Collins, 2012). In addition to the H5N1, the first human case with AIV H7N9 was confirmed by the WHO in 2013. The H7N9 is highly pathogenic in humans with CFR > 36\% and the virus has pandemic potential (Su et al., 2015; Tanner et al., 2015).

A Rapid, specific, and sensitive detection of the virus is crucial to aid infection control and public health responses during influenza outbreaks (WHO, 2009; Dunn, and Ginocchio, 2014). Current virus detection techniques are available, such as virus isolation, ELISA, and RT-PCR (Leland and Ginocchio, 2007; Ho et al., 2009; Ng et al., 2005). Virus isolation has been the "gold standard" due to the highest sensitivity and reliability, but it is a very time-consuming procedure (4-7 days). ELISA is a simple and rapid test in processing mass serum samples, thus it is commonly used for serum antibody detection, but not for virus detection in practice or diagnostics. RT-PCR and real- 
time RT-PCR methods have the advantages of high sensitivity and specificity, but possess disadvantages of requiring expensive PCR equipment and reagents, qualified laboratory facilities and well-trained technical personnel. Rapid influenza diagnostic tests (RIDTs) are simple to use and can provide results within 15 minutes (Bose et al., 2014). Nevertheless, RIDTs have poor sensitivity compared to the virus isolation and RT-PCR detection methods (Drexler et al., 2009; Chan et al., 2012).

A promising alternative to above detection assays is biosensors technology. Several biosensors have been developed to detect AIV. Previously Yanbin Li's group reported successful use of impedance immunosensors. Wang et al. (2009) reported the development of an impedance immunosensor based on an interdigitated array (IDA) microelectrode for H5N1 detection. Wang et al. (2011) also reported an impedance biosensor for H5N2 avian influenza detection based on a combination of immunomagnetic nanobeads, and a microfluidic chip with an IDA microelectrode. Then, Lum et al. (2012) further improved the impedance biosensor for H5N1 detection by a combination of immunomagnetic nanoparticles, a microfluidic chip, an interdigitated microelectrode and red blood cells (RBCs) for signal amplification. Other types of biosensors have also been developed for avian influenza detection, such as magnetic nanobeads amplification based quartz crystal microbalance (QCM) immunosensor for H5N1 detection (Li et al., 2011). H7N2, H7N3, and H8N4 subtypes were detected by an interferometric biosensor immunoassay through virus capture on a planar optical waveguide (Xu et al., 2007). Moreover, swine-origin influenza A (H1N1) virus (S-OIV) was detected by a paired surface plasma waves biosensor (PSPWB) in a dual-channel biosensor (Su et al., 2012). Detection methods based on biosensors are characterized by accuracy, speed, ease of use, low cost, and portability.

Aptamers are artificial nucleic acid ligands that can bind to target molecules and they are generated 
by an in vitro selection process called SELEX (Tuerk and Gold., 1990). Recently, our research group developed a DNA aptamer that can bind specifically to H5N1 virus with high affinity, dissociation constant $\left(K_{\mathrm{D}}\right)$ of $4.65 \mathrm{nM}$ (Wang et al., 2013a). Aptamers offer several advantages over antibodies. They are stable at room temperature, simple to synthesize, easily modified chemically, with low structural variation during chemical synthesis, and low cost of production (Sun et al., 2014). We have developed several aptasensors based on this aptamer. Here, three of them have highlighted: (i) the H5N1 DNA-aptamer was used as a specific recognition element in a portable Surface Plasmon Resonance (SPR) biosensor for rapid detection of AIV H5N1 in poultry swab samples (Bai et al., 2012); (ii) a quartz crystal microbalance (QCM) aptasensor was developed based on the H5N1 DNA aptamer crosslinked polymeric hydrogel for detection of AIV H5N1 (Wang et al., 2013b); (iii) a novel impedance biosensing method was developed by exploiting the enzyme catalysis in ultra-low ion strength media to induce ion strength increase in the detection of H5N1 (Fu et al., 2014). These aptasensors showed improved sensitivity in detection compared to immunosensors.

In this study, we describe an impedance biosensor based on aptamers and IDA microelectrode for rapid detection of $\mathrm{H} 5 \mathrm{~N} 1$ influenza virus. The main innovation of this study was to use a networklike thiocyanuric acid/gold nanoparticles as an amplifier for dramatically enhancing detection signal. In addition, the AIV H5N1 specific aptamer was used as affinity ligand instead of antibody, and IDA microelectrode was employed for impedance measurement. This report provides a foundation for the development of a robust and sensitive impedance aptasensor and its application for rapid detection of $\mathrm{H} 5 \mathrm{~N} 1$.

\section{Materials and methods}




\subsection{Viruses and aptamers}

The stock concentration of viruses was 128 hemagglutination units (HAU) /50 $\mu$ l. The virus was inactivated by the USDA with b-propiolactone, eliminating viral infectivity while preserving hemagglutination activity (Goldstein and Tauraso, 1970). The virus was diluted in PBS (10 mM, $\mathrm{pH} 7.4$ ) at a range from 16 to $0.125 \mathrm{HAU}$ in $50 \mu \mathrm{l}$ and only $30 \mu \mathrm{l}$ were used for the assay on the surface of microelectrodes. Inactivated normal AIV (A/chicken/Scotland/59(H5N1)) was supplied from the USDA/APHIS National Veterinary Services Lab (Ames, IA, USA). Inactivated nontarget AIV subtypes of A/H5N2/PA/chicken/85, A/H5N3/WileyLab/87, A/H7N2/PA/chicken/3779-2/97, A/H1N1/WileyLab/87, and A/H2N2/PA/chicken/ 1117-6/04 were from Animal Diagnostic Laboratory (ADL), at Pennsylvania State University (University Park, PA, USA). They were diluted in PBS with titer of $16 \mathrm{HAU}$ in $50 \mu \mathrm{l}$. Because of biosecurity requirement in handling live AIV strains and the biosafety limitation of our laboratory condition (biosafety level 2), only inactivated AIV strains were used in this study. The selected aptamer with high affinity and specificity against AIV H5N1 was developed in our research group (Wang et al., 2013a). Biotinylated aptamer and amine modified aptamer were obtained from Integrated DNA Technologies, Inc. (Coralville, IA, USA). The sequences are: 5'-Biotin-GTG TGC ATG GAT AGC ACG TAA CGG TGT AGT AGA TAC GTG CGG GTA GGA AGA AAG GGA AAT AGT TGT CCT GTT G-3' and 5'-/5AmMC6/GTG TGC ATG GAT AGC ACG TAA CGG TGT AGT AGA TAC GTG CGG GTA GGA AGA AAG GGA AAT AGT TGT CCT GTT G-3' respectively.

\subsection{The IDA microelectrodes}

The microelectrode has 25 digital pairs with $15 \mu \mathrm{m}$ digit width and $15 \mu \mathrm{m}$ interdigit spaces. The total area of the IDA microelectrode was $\sim 77 \mathrm{~mm}^{2}$ with a working area of $\sim 4.5 \mathrm{~mm}^{2}$. It was 
fabricated at the State Key Lab of Integrated Optoelectronics at the Institute of Semiconductor, Chinese Academy of Science.

\subsection{Preparation of gold IDA microelectrodes}

First, the gold IDA microelectrodes were checked under a microscope to be sure that all the 25 paired digits were intact. Washing of the microelectrodes were done in three steps. At the beginning, $30 \mu \mathrm{l}$ of $1 \mathrm{M} \mathrm{NaOH}$ was added to surface of the microelectrodes and incubated for 10 min at room temperature (RT). Then, $30 \mu \mathrm{l}$ of $1 \mathrm{M} \mathrm{HCl}$ was added to the microelectrodes and incubated for 5 min at RT. Finally, they were rinsed with EtOH and softly wiped with lens paper. At the end of each step, microelectrodes were washed thoroughly with ultra-pure water and dried under a stream of $\mathrm{N}_{2}$ gas. The electrodes were considered clean if the recorded impedance was under $200 \mathrm{ohms}$ at $100 \mathrm{~Hz}$ frequency.

\subsection{Modification of gold IDA microelectrodes}

Streptavidin (Rockland, Gilbertsville, PA, USA) was immobilized on the surface of microelectrodes through physical adsorption $(1 \mathrm{mg} / \mathrm{ml})$. The microelectrodes were washed thoroughly with ultra-pure water to remove unbound proteins and dried out at RT. Then, biotinylated $\mathrm{H} 5 \mathrm{~N} 1$ aptamers were bound to the immobilized streptavidin on the microelectrodes (20 ng/ $\mu \mathrm{l})$. The microelectrodes were washed thoroughly to remove the unbound aptamers and dried out. Later, blocking of the microelectrodes was done with poly(ethylene glycol) methyl ether thiol (PEG, $0.1 \mathrm{mg} / \mathrm{ml})$. Finally, the microelectrodes were washed and dried out at RT. Each incubation step was carried out at RT for $45 \mathrm{~min}$ and the volumes on the surface of microelectrodes were $30 \mu \mathrm{l}$. After each step, impedance of the microelectrodes was measured.

\subsection{Preparation of amplifiers}


AuNPs (gold nanoparticles) were synthesized by sodium citrate reduction of $\mathrm{HAuCl}_{4}$ ( $\mathrm{Liu}$ and $\mathrm{Lu}$, 2006). The diameter of AuNPs was $\sim 14 \mathrm{~nm}$ and the size of AuNPs was checked by using TEM. One milliliter of the AuNPs was centrifuged at 20,000 x $g$ for 20 min. The supernatant was aspirated and the AuNPs pellet was suspended in $10 \mathrm{mM}$ Dithiodipropionic acid di(Nhydroxysuccinimide ester) (DTSP) a protein cross linker (Sigma-Aldrich (St. Louis, MI, USA)). The surface of AuNPs was functionalized with DTSP by incubation at RT for $3 \mathrm{hrs}$. Then AuNPs were centrifuged at 20,000 $\mathrm{g}$ for $5 \mathrm{~min}$. The pellet was resuspended in $1 \mathrm{ml}$ of the amine modified H5N1 aptamers and incubated for 1 hour at RT. This allowed the formation of labeled AuNPs with H5N1 aptamers. Finally, $50 \mu 1$ of thiocyanuric acid $(60 \mathrm{mg} / \mathrm{ml})$ (TCI America (Portland, OR, USA)) was added to create a network like structure in an hour incubation at RT.

\subsection{Impedance measurement and $\mathrm{H} 5 \mathrm{~N} 1$ detection}

H5N1 virus detection was based on streptavidin/aptamer/virus complex formation. The H5N1 viruses were captured by the H5N1 DNA aptamers that were bound to the immobilized streptavidin on the IDA microelectrode, which resulted in an increase of the impedance. Thirty microliters of H5N1 virus was dropped onto the microelectrode, followed by incubation for 45 min, washing with ultra-pure water, drying out at RT, and impedance measurement. For detection signal amplification, $30 \mu \mathrm{l}$ of amplifier was applied to the surface of microelectrode and incubated for $45 \mathrm{~min}$. Then, it was washed with ultra pure water and dried out at RT. Impedance and phase angle measurements were done using an IM-6 impedance analyzer with the IM-6/Thales 2.49 software (Bioanalytical Systems, West Lafayette, IN, USA). Test-sense and counter-reference probes were connected to the IDA microelectrode array with connecting wires. In all impedance measurements, a sinusoidal $\mathrm{AC}$ potential of $10 \mathrm{mV}$ was applied. Then, impedance magnitude and phase angle were measured at 54 points in the frequency range from $10 \mathrm{~Hz}$ to $1 \mathrm{MHz}$ in the 
presence of $10 \mathrm{mM}\left[\mathrm{Fe}(\mathrm{CN})_{6}\right]^{3-14-}(1: 1)$ mixture redox probes in PBS (pH 7.4). The impedance change was calculated as the difference before and after virus attachment on the microelectrodes. 2.7. Conventional RT-PCR and Real-time RT-PCR

Conventional RT-PCR was performed according to the WHO information for molecular diagnosis of influenza virus (WHO, 2014). The used primers were M30F2/08 5'ATGAGYCTTYTAACCGAGGTCGAAACG-3' and ${ }^{\prime}$ ' TGGACAAANCGTCTACGCTGCAG-3'. RNA was isolated from 128 HAU/50 $\mu 1$ stock with a QIAamp viral RNA mini kit (Qiagen, Valencia, CA) according to the instructions from the manufacturer. Sixty microliters of AVE buffer was used for elution of the $128 \mathrm{HAU}$ virus. The AVE buffer contains RNase-free water with $0.04 \% \mathrm{NaN}_{3}$ (Sodium azide). Fifteen microliters of the purified RNA was subjected to reverse transcription using M-MuLV reverse transcriptase (NEB, Ipswich, MA, USA) and M264R3/08 primer in a total volume of $20 \mu 1$ following the provider's protocol. Taq DNA Polymerase (NEB, Ipswich, MA, USA) was used to reamplify the viral cDNA in a total volume of $50 \mu 1$ using M30F2/08 and M264R3/08 primers following the manufacture's instruction. At this step, the viral cDNA was two-fold serially diluted for PCR amplification at a range from 16 to $0.125 \mathrm{HAU}$. PCR conditions were as follows: $95^{\circ} \mathrm{C}$ for $30 \mathrm{sec}$, followed by 45 cycles of $95^{\circ} \mathrm{C}$ for $30 \mathrm{sec}, 50^{\circ} \mathrm{C}$ for $30 \mathrm{sec}$, and $68^{\circ} \mathrm{C}$ for $1 \mathrm{~min}$, with a final extension step at $68^{\circ} \mathrm{C}$ for $5 \mathrm{~min}$. The $244 \mathrm{bp}$ of amplified matrix gene (20 $\left.\mu \mathrm{l} / \mathrm{lane}\right)$ was checked on 2\% agarose gel electrophoresis. Real-time RT-PCR (rRT-PCR) was conducted at Wiley lab at Pennsylvania State University according to the USDA National Veterinary Services Laboratories (NVSL), document number SOP-AV-1510.07. The viral RNA concentration from 16 to 0.125 HAU was subjected to rRT-PCR. The used primers and probes that target Matrix gene were M+25

5 ' -AgAtgAGtCTtCTAACCGAGGTCG-3 ' , M-124 5 ' - 
TGCAAAAACATCTTCAAGTCTCTG-3 ' ; and $5^{\prime}$-FAM-TCAGGCCCCCTCAAAGCCGA-

BHQ-1-3'. Amplification was performed with the One-Step RT-PCR Kit (Qiagen, Valencia, CA, USA) in a 7300 Real Time PCR System (Applied Biosystems, Foster City, CA, USA). PCR conditions were as follows: $50^{\circ} \mathrm{C}$ for $30 \mathrm{~min}, 95^{\circ} \mathrm{C}$ for $15 \mathrm{~min}$ followed by 45 cycles of $95^{\circ} \mathrm{C}$ for $10 \mathrm{sec}$, and $60^{\circ} \mathrm{C}$ for $1 \mathrm{~min}$. The samples have cycle threshold $(\mathrm{Ct})$ values of less than 30 were considered positive.

\subsection{Chicken tracheal samples}

Swab samples were collected from trachea of healthy chickens at 40 days of age at the John Kirkpatrick Skeeles Poultry Health Laboratory, at the University of Arkansas. The swab sampling and experiment were approved by the Institutional Animal Care and Use Committee (IACUC) at the University of Arkansas. Three swabs were pooled and placed into a sterile tube containing 3 $\mathrm{ml}$ of PBS. To process the swabs for testing, all swabs were vortexed vigorously for $15-20 \mathrm{~s}$ and then the swab was pressed against the inside of the tube to squeeze and remove as much of the organic material as possible. The liquid swab samples were kept at $4^{\circ} \mathrm{C}$ in a refrigerator for $1 \mathrm{~h}$ to allow large particles and organic materials to precipitate to the bottom of the test tube. The supernatant of samples were then stored at $-80^{\circ} \mathrm{C}$ in a freezer until use. Before impedance testing, the swab samples were thawed at room temperature and filtered through $0.45 \mu \mathrm{m}$ filter. The filtrate was spiked with the H5N1 virus stock to make appropriate titers of the virus for aptasensor detection.

2.9. Statistical analysis 
Microsoft Excel (Microsoft, Redmond, VA, USA) was used for statistical analysis of all data, including calculation of means, standard deviation, and t-tests.

\section{Results}

\subsection{Impedance aptasensor system}

The detection procedures and impedance measurement on the IDA microelectrode is shown in Fig. 1. Briefly, streptavidin was immobilized on the surface of microelectrode, then biotinylated H5N1 specific aptamer was bound to the streptavidin. After this modification, the microelectrode was blocked with poly(ethylene glycol) methyl ether thiol. Next, the H5N1 influenza sample was suspended in PBS and dropped on the microelectrode. The $45 \mathrm{~min}$ incubation allowed the virus to bind to the aptamer and formed a complex of streptavidin, aptamer, and H5N1 virus. The microelectrode was then washed with water to remove unbound viruses. Change in the impedance of the streptavidin/aptamer/virus complex on the microelectrode was measured and correlated to the presence of target influenza virus. Further, to amplify the detection signal, a network like structure amplifier that was made from AuNPs/protein cross linker/aptamer/thiocyanuric acid was added to bind the viruses on the microelectrode. The measured impedance value of each step in the microelectrode surface modification and virus detection is shown in Fig. 2. The impedance magnitude of each step in the modification of the microelectrode surface and detection of H5N1 with amplifier labels was recorded in a Bode plot as shown in Fig. 3(A). At a frequency of 100 $\mathrm{Hz}$, the change of impedance was recorded. The maximum impedance change with less noise was observed at $100 \mathrm{~Hz}$ (Lin et al., 2014). The impedance of cleaned bare microelectrode was $140 \Omega$. After streptavidin immobilization, impedance increased to $260 \Omega$. Then, aptamer binding resulted in an increase of impedance to $313 \Omega$. Blocking with the polyethylene glycol further increased the 
impedance to $344 \Omega$. The capture of virus $(0.5 \mathrm{HAU})$ onto the microelectrode caused an increase in the impedance magnitude to $464 \Omega$ compared to the control sample (PBS). Finally, the amplifier elevated the impedance to $16,800 \Omega$ compared to the control sample (PBS). Results of the impedance changes caused by different concentrations of captured H5N1 viruses and amplifier were presented in Fig. 3(A) and Table 1. The phase angle was also recorded for all impedance measurements as shown in Fig. 3(B). The phase angle describes the contributions of the resistive and capacitive portions to the impedance magnitude. The phase angle peak of bare microelectrode was $-11^{\circ}$ at $250 \mathrm{kHz}$ frequency. The $\mathrm{H} 5 \mathrm{~N} 1$ virus shifted the phase angle to $-51^{\circ}$ at the frequency of $51.4 \mathrm{kHz}$, and the amplifier further shifted the phase angle to $-81^{\circ}$ at the frequency of $5.2 \mathrm{kHz}$.

\subsection{Characterization of the impedance data}

The impedance spectrum for each step in the modification of the microelectrode and the detection of $\mathrm{H} 5 \mathrm{~N} 1$ virus at a frequency range of $10 \mathrm{~Hz}$ to $1 \mathrm{MHz}$ were recorded in a Bode plot as shown in Fig. 3(A). The binding of streptavidin, aptamer, PEG, and H5N1 virus onto the microelectrode's surface caused an increase in the impedance magnitude of the microelectrode sequentially. For a better understanding of the measured impedance data, a model shown in Fig. 4(A) was used as the equivalent circuit for simulation. The circuit consists of four elements: electron transfer resistor $\left(R_{e t}\right)$, double layer capacitance $\left(C_{\mathrm{dI}}\right)$, the resistance of the solution $\left(R_{\mathrm{S}}\right)$, Warburg impedance or interfacial impedance $\left(W_{\mathrm{z}}\right)$. The $R_{\mathrm{et}}$ represents the resistance of the electron transfer of the redox probes, the $C_{\mathrm{dI}}$ component represents the effect of ions near the surface of the electrodes, the $\mathrm{R}_{\mathrm{s}}$ represents the resistance of the bulk electrolyte solution, and the $W_{\mathrm{z}}$ represents diffusion of species into the electrode. Fig. 4(B) shows the experimental data compared to the simulated data generated using the equivalent circuit. The equivalent circuit was validated using the IM-6/Thales software (Bioanalytical Systems, West Lafayette, IN, USA). The software selected 54 points from the 
experimental data to fit a simulated impedance spectrum. The mean error of the impedance magnitude was $1.3 \%$ and the mean error of the phase angle was $1.4^{\circ}$ after fitting $\mathrm{H} 5 \mathrm{~N} 1$ values on the model. The percent increase in $R_{\text {et }}$ between control (before adding the virus) and virus was $164 \%$, and the change in $R_{\mathrm{s}}$ was $36 \%$, while percent increase in $C_{\mathrm{dI}}$ and $W_{\mathrm{z}}$ were only $7 \%$ and $8 \%$, respectively.

\subsection{Detection limit of the impedance aptasensor}

Detection limit of the aptasensor plays an essential role and it could be a crucial factor to decrease the false positive from false negative ratio during detection. To do this, a series of 2 -fold dilutions of the H5N1 virus were prepared in PBS and then detected using the impedance aptasensor. The results of these studies are presented in Fig. 5. Triplicate tests were conducted for each virus concentration in the range of 16 to $0.125 \mathrm{HAU} / 50 \mu \mathrm{l}$, with PBS as a negative control. The impedances obtained at virus titer lower than $0.25 \mathrm{HAU}$ were poorly discriminated because their signal did not exceed 3 times the standard deviation from the control measurement. Further, the impedance obtained at virus concentration $0.25 \mathrm{HAU}$ was significantly different $(P<0.05)$ compared to the signal of the control measurement; the impedance obtained at virus concentration 0.125 was not significantly different $(P>0.05)$ compared to the signal of the control measurement. The mean impedance \pm SD for $0.25,0.125 \mathrm{HAU}$, and PBS were $59 \pm 20 \Omega, 0 \pm 3 \Omega$, and $4 \pm 3 \Omega$ respectively. Linear relationship between impedance change and logarithmic value of H5N1 virus concentration was found in the range of 16 to $0.25 \mathrm{HAU} / 50 \mu \mathrm{l}$ and can be described as $\Delta \mathrm{Z}=$ 30.11 $\log _{2}(\mathrm{x})+123.69\left(\mathrm{R}^{2}=0.88\right)$. The lower limit of detection of this impedance aptasensor was determined based on signal to noise ratio $\geq 3$, i.e. maximum standard deviation of the control measurements $\times 3$ (Lin et al., 2014), and was found to be 0.25 HAU.

\subsection{Amplification of the detection signal}


The formation of the sandwich like format of streptavidin/aptamer/virus/amplifier (aptamer/AuNPs/TCA) was investigated through the change in impedance. As shown in Table 1, the presence of amplifier resulted in an enhanced impedance change. Triplicate tests were conducted for pure virus concentrations of $2,1,0.5,0.25$, and $0.125 \mathrm{HAU} / 50 \mu 1$ with PBS as a negative control. At a virus titer of $2 \mathrm{HAU}$, a 116 fold increase of impedance was observed after addition of the amplifier to the surface of microelectrode. Also, the virus titers of $1,0.5$, and 0.25 HAU increased the impedance signal by a 47, 96, and 152 fold, respectively. Even though a virus titer of $0.125 \mathrm{HAU}$ increased the impedance, it was not considered an increase of signal because the impedance change was smaller than 3 times of the standard deviation of negative samples (PBS). Further, the amplified signal of virus concentrations of 2, 1, 0.5, and $0.25 \mathrm{HAU}$ was significantly different $(p<0.05)$ compared to the amplified signal of the negative samples. However, the amplified signal of a virus concentration of 0.125 HAU was not significantly different $(p>0.05)$ compared to the amplified signal of negative samples. Moreover, triplicate tests were conducted for trachea swabs spiked with virus concentrations of $2,1,0.5$, and 0.25 HAU/50 $\mu \mathrm{l}$ with a negative filtrate control being used. At the spiked virus titer of 2 HAU, a 139 fold increase of impedance was observed after addition of the amplifier to the surface of the microelectrode. Also, the virus/amplifier titers of 1, 0.5, and $0.25 \mathrm{HAU}$ increased the impedance signal by 57,72 and 48 fold, respectively.

\subsection{Specificity of the aptasensor}

The specificity of this aptasensor is mainly dependent on the aptamers that bind H5N1 virus, which were bound with the streptavidin immobilized on the surface of microelectrodes. The aptasensor was evaluated for specificity with five different subtypes of influenza viruses using the same procedure as described previously for testing H5N1 virus. The frequency of $100 \mathrm{~Hz}$ was chosen 
for evaluation of the specificity tests. As shown in Fig. 6, the mean impedance changes of H5N1, $\mathrm{H} 5 \mathrm{~N} 2, \mathrm{H} 5 \mathrm{~N} 3, \mathrm{H} 7 \mathrm{~N} 2, \mathrm{H} 1 \mathrm{~N} 1$, and $\mathrm{H} 2 \mathrm{~N} 2$ at a titer of $16 \mathrm{HAU} / 50 \mu \mathrm{l}$ were measured. The impedance changes resulting from the non-target viruses were negligible $(-23 \pm 34 \Omega$ for $\mathrm{H} 5 \mathrm{~N} 2,16 \pm 19 \Omega$ for $\mathrm{H} 5 \mathrm{~N} 3,52 \pm 11 \Omega$ for $\mathrm{H} 7 \mathrm{~N} 2,9 \pm 30 \Omega$ for $\mathrm{H} 1 \mathrm{~N} 1$, and $-3 \pm 13 \Omega$ for $\mathrm{H} 2 \mathrm{~N} 2$, respectively) compared to that resulting from $\mathrm{H} 5 \mathrm{~N} 1$ virus $(282 \pm 21 \Omega$ for $\mathrm{H} 5 \mathrm{~N} 1)$.

\subsection{H5N1 detection with conventional RT-PCR and rRT-PCR}

The stock purified influenza H5N1virus with a titer of $128 \mathrm{HAU} / 50 \mu \mathrm{l}$ were used to perform conventional RT-PCR. RNA was purified from $50 \mu 1$ of the virus stock and cDNAs that made with M264R3/08 primer were diluted in a series of 2-fold dilutions at a range from 16 - 0.125 HAU. The cDNAs were subject to PCR with M30F2/08 and M264R3/08 primers that are recommend by WHO for detection of influenza A virus. As shown in Fig. 7, virus at concentrations of 16, 8, 4, 2, 1, and 0.5 HAU were PCR positive and those lower than 0.5 HAU were PCR negative. The RNA extract were subjected to rRT-PCR with primers and probe that are recommended by NVSL for detection of influenza A virus. As shown in Fig. 8(A), H5N1 virus concentration from 16 to 0.125 HAU were positive. The Ct values for $16,8,4,2,1,0.5,0.25$, and 0.125 HAU were 14.97, 15.49, 16.23, 17.06, 18.03, 18.82, 20.00, and 21.66 respectively. Linear relationship between $\mathrm{Ct}$ value and logarithmic value of $\mathrm{H} 5 \mathrm{~N} 1$ virus concentration was found in the range of 16 to $0.125 \mathrm{HAU}$ and can be described as $C t=-0.93 \log _{2}(x)+18.24\left(R^{2}=0.98\right)$. A linear relationship was found between the reading from impedance change measured by the aptasensor and the Ct value tested by rRT-PCR Fig. 8(B), in the virus titer range from 16 to 0.125 HAU and can be described as $y=$ $-0.026 x+21.28\left(R^{2}=0.90\right)$, where $y$ is reading of $C t$ value from rRT-PCR and $x$ is reading of impedance change from the aptasensor. 


\section{Discussion}

The need to develop more sensitive and rapid influenza virus detection tests has prompted researchers to employ Electrochemical Impedance Spectroscopy (EIS) for virus detection. We evaluate the performance of a newly developed impedance aptasensor by detecting cultured inactivated H5N1 virus and the use of an amplifier for enhancement of detection signal. The impedance aptasensor is based on measurements of Faradaic impedance in the presence of $\left[\mathrm{Fe}(\mathrm{CN})_{6}\right]^{3-14-}$ as a redox probe (Yang et al., 2004). The electron transfer of $\left[\mathrm{Fe}(\mathrm{CN})_{6}\right]^{3-14-}$ can be blocked by the formation of biolayers on the electrode surface, which results in an increase of the electron transfer resistance of $\left[\mathrm{Fe}(\mathrm{CN})_{6}\right]^{3-14-}$ probe. This blockage by streptavidin, aptamer, PEG, virus, and amplifier was clearly presented in Fig. 3. In the described aptasensor, the formation of the biolayers on the electrode surface inhibited the flow of ions between the microelectrode fingers. Therefore, the number of captured viruses by the aptamers is related to the titer of target viruses in solution, and detection would be performed by measuring the change of the electron transfer resistance of $\left[\mathrm{Fe}\left(\mathrm{CN}_{6}\right)\right]^{3-1 / 4}$ probe on the microelectrode. Moreover, simulations with an equivalent circuit model were used to better interpret the impedance data. The experimental data was compared to the simulated data generated using the equivalent circuit. The percent increase in $R_{\mathrm{et}}$ between control and virus by $164 \%$ confirmed that the majority of the impedance change between detection steps was due to a change in the electron transfer resistor.

One criteria of a robust detection method is low detection limit. The lowest titer of the H5N1 virus detected with this impedance aptasensor was $30 \mu \mathrm{l}$ of $0.25 \mathrm{HAU} / 50 \mu \mathrm{l}$ pure virus. Detection limit of the three previously mentioned aptasensors for $\mathrm{H} 5 \mathrm{~N} 1$ detection in our lab were $8 \times 10^{-4} \mathrm{HAU}$ in $200 \mu \mathrm{l}$ (Fu et al., 2014), $0.0128 \mathrm{HAU}$ in $200 \mu \mathrm{l}$ (Wang et al., 2013b), and 0.128 HAU in $300 \mu \mathrm{l}$ (Bai et al., 2012). The volume of the tested virus in this study was reduced to $30 \mu$, which is an 
advantage in detection of small sample volume. In addition, Lin et al., (2014) reported an impedance immunosensor for detection of $\mathrm{H} 5 \mathrm{~N} 1$ in chicken swab samples with detection limit of 0.5 HAU/50 $\mu 1$ and Kim et al., (2014), developed a QCM immunosensor for detection of H3N2 canine influenza virus in canine saliva samples with a detection limit of 4 HAU. To use the aptasensor in the field for detecting $\mathrm{H} 5 \mathrm{~N} 1$, it will require a ready to use microelectrode, PBS, syringe, a portable small impedance analyzer, and 55 min (incubation, washing, drying, and testing), this is without amplifier, needs another $55 \mathrm{~min}$ if amplifier applies. The components and reagents needed for aptasensor development are inexpensive. The estimation cost of the reagents (streptavidin, aptamer, PEG, and AuNPs et al) for one test is about $\$ 1$ (labor not included). The only expensive part in the aptasensor is microelectrode. However, the cost of the microelectrode was significantly reduced through employing wet-etching process for the microelectrode fabrication (Lin et al., 2014). Currently, the cost of a test is about $\$ 13$ but mass production of the microelectrode for commercial purposes will drop the cost to under $\$ 3$. In addition, the microelectrode can be continuously used until a positive sample is met. The microelectrode made our aptasensor to be cheaper than the previously reported aptasensors. For instance, Wang et al. (2013b) used commercial quartz crystals with gold electrodes evaporated on both sides, and the cost of one quartz crystal electrode is $\$ 19.97$; Lum et al. (2015) used interdigitated electrode based microfluidic chip and one chip costs $\$ 100$ at the research stage. These detection platforms are sensitive and specific, but more expensive when compared to the aptasensor developed in this study.

It would be helpful to know how many virus RNA copy numbers are in a HAU for detection limit interpretation. Shin et al., (2010) reported that detection limit of conventional RT-PCR with WHO 
influenza A common matrix gene primers is 10 RNA copies for RNA standards, in vitro transcribed RNA. In this study, the lowest virus titer detected by using conventional RT-PCR with the WHO primers was 0.5 HAU. Since the detection limit of this aptasensor is $0.25 \mathrm{HAU}$, a conclusion can be drawn that the aptasensor sensitivity is equal to or better than the conventional RT-PCR. However, the aptasensor did not detect the virus titer at $0.125 \mathrm{HAU}$ but the real time PCR was able to detect 0.125 HAU.

The specificity of H5N1 aptasensor was investigated by testing related influenza viruses that belong to the different subtypes. The specificity of the aptasensor is mainly dependent upon the aptamers. Therefore, the combination of specific aptamers that bind to the H5N1 virus hemagglutinin (HA) protein is a logical approach for highly specific detection of H5N1, minimizing interferences from other influenza virus subtypes. The impedance resulting from these non-H5N1 viruses was negligible. The titer of 16 HAU of H5N2, H5N3, H7N2, H1N1, and H2N2 was unable to provide significant increase in impedance. The negative value of $\mathrm{H} 5 \mathrm{~N} 2$ and $\mathrm{H} 2 \mathrm{~N} 2$ subtypes were possibly due to a washing step. The aptamer did not bind to the non-specific viruses and the washing step removed a few streptavidin molecules, which resulted in a negative impedance value. Even though hemagglutinin sequence similarity between $\mathrm{H} 5 \mathrm{~N} 1$ and $\mathrm{H} 5 \mathrm{~N} 2$ is more than $90 \%$, the aptamer still cannot bind to the H5N2. This indicates the specificity of the aptamer to only H5N1 virus. Further, this aptamer showed non-specificity to H5N2, H5N3, and H5N9 when it was used as a capturing agent in developing other aptasensors (Bai et al., 2012; Fu et al., 2014; Xu et al., 2016). The H5N1 A/Chicken/Scotland/59 used in this study is historical Eurasian H5N1 clade zero (WHO, 2007). Wang et al., (2013a) showed that this aptamer binds specifically to the clade 1, the H5N1 A/Vietnam/1203/04 (Sansyzbay et al., 2013) and the clade 
2.3.2, the A/Duck/Guangdong/383/2008 (Sun et al., 2011). Collectively, this indicates that the aptamer has strong specificity to the tested H5N1 clades.

Amplifying the detection signal is essential for sensitive and reproducible biosensing. The employed amplifier enhanced the signal for H5N1 detection. Amine modified H5N1 aptamers were covalently bound to AuNPs through reactive succinimidyl group of the DTSP. To form network-like thiocyanuric acid-AuNPs, three thiol groups of each thiocyanuric acid molecules bind strongly to AuNPs. Therefore, AuNPs continue to bind to each other through thiocyanuric acid to amplify the amount of AuNPs to form the amplifier network (Zheng et al., 2007). The dramatic impedance increase was an indicator that the amplifier strongly blocked the electron transfer of redox probe. The impedance change of pure virus at titer of $0.25 \mathrm{HAU}$ with amplifier was a 152 fold increase and the impedance change of virus spiked with tracheal swab sample at titer of $0.25 \mathrm{HAU}$ with amplifier was 48 fold. This reveals the crucial role of the amplifier in enhancement of the detection signal with potential to identify a lower quantity of targeted virus. However, the amount of amplifier needs to be carefully controlled to minimize background noise and work in a dose-dependent manner. This noise may happen due to the binding of some AuNPs to the gold surface of the microelectrodes through thiocyanuric acid. The microelectrodes were blocked with PEG, but it is possible that the blocking efficiency is insufficient. Since thiocyanuric acid binds to gold, the interaction between the AuNPs and microelectrodes may cause this noise, which will then be recorded for this aptasensor when the amplifier is used. A better blocking reagent will be addressed in our future research.

RT-PCR is considered a specific and sensitive method for detection of influenza virus. With the development of real time PCR, application of conventional PCR has diminished. However, 
conventional RT-PCR for influenza A detection is still in the manuals of WHO for detection. A point of interest would be to compare the detection limit of the aptasensor method with the conventional PCR method. The lowest virus concentration detected by the conventional RT-PCR method for cultured inactivated H5N1 was 0.5 HAU. The rRT-PCR showed superiority detecting lowest virus titer in our experiment, 0.125 HAU. However, the rRT-PCR did this detection in a few hours and consumes many expensive reagents; the developed aptasensor simple, fast, and cheap. In comparing our assay to reverse transcriptase loop-mediated isothermal amplification (RT-LAMP), the latter one requires a laboratory to extract viral RNA and perform the enzymatic reaction for the RNA amplification and it takes about one hour incubation in a water bath or heat block to get results (Dinh et al., 2011). Our aptasensor does not require a laboratory; it can be performed at the site of AIV sampling. The aptasensor requires less time for AIV detection compared to RT-LAMP since it does not require RNA extraction from the sample. The detection limit of the real-time RT-LAMP was approximately 1,000-fold lower than the real-time RT-PCR (Postel et al., 2010). This indicates that the detection limit of the aptasensor is not lower than the RT-LAMP. Due to high variability of the sequence of the hemagglutinin, the assays are vulnerable when it comes to the specificity. However, the aptamer used in the aptasensor was specifically bound to the old H5N1 clade and the current circulating common clade (2.3.2).

\section{Conclusions}

In this study, an impedance aptasensor was developed for rapid detection of avian H5N1 virus in less than 1 hour. A linear relationship between impedance change and logarithmic value of pure $\mathrm{H} 5 \mathrm{~N} 1$ virus concentration was found in the range of 16 to $0.125 \mathrm{HAU}$. The amplifier based on gold-nanoparticle/protein cross linker/H5N1 aptamer/thiocyanuric acid was shown to increase the 
impedance signal change by at least a 48 fold compared to the protocol without the amplifier in the tracheal samples spiked with H5N1 virus. Tests with H5N1 and non-target influenza subtypes showed that the biosensor was able to specifically detect subtype H5N1 by specific aptamers which bound to the virus. This aptasensor provided a simple, rapid, robust, cost-effective, and reliable detection method.

\section{Acknowledgments}

The first author thanks KRG-HCDP for the fellowship support. This study was supported in part by Arkansas Biosciences Institute (Project \# 0383-43052-24-2099) and in part by USDA/NIFA (Project \# 20093560305063).

\section{Conflicts of interest}

No conflicts of interest were declared in relation to this article.

\section{References}

Bai, H., Wang, R., Hargis, B., Lu, H., Li, Y., 2012. A SPR aptasensor for detection of avian influenza virus H5N1. Sensors 12, 12506-12518.

Bose, M. E., Sasman, A., Mei, H., McCaul, K. C., Kramp, W. J., Chen, L., Shively, R., Williams, T. L., Beck, E. T., Henrickson, K. J., 2014. Analytical reactivity of 13 commercially available rapid influenza diagnostic tests with $\mathrm{H} 3 \mathrm{~N} 2 \mathrm{v}$ and recently circulating influenza viruses. Influenza Other Respir. Viruses 8, 474-481. 
Chan, C.H., Lin, K.L., Chan, Y., Wang, Y.L., Chi, Y.T., Tu, H.L., Shieh, H.K., Liu, W.T., 2006. Amplification of the entire genome of influenza A virus H1N1 and H3N2 subtypes by reversetranscription polymerase chain reaction. J. Virol. Methods. 136, 38-43.

Chan, K.H., Chan, K.M., Ho, Y.L., Lam, Y.P., Tong, H.L., Poon, L.L., Cowling, B.J., Peiris, J.S., 2012. Quantitative analysis of four rapid antigen assays for detection of pandemic H1N1 2009 compared with seasonal $\mathrm{H} 1 \mathrm{~N} 1$ and $\mathrm{H} 3 \mathrm{~N} 2$ influenza A viruses on nasopharyngeal aspirates from patients with influenza. J. Virol. Methods 186,184-188.

Dinh, D.T., Le, M.T., Vuong, C.D., Hasebe, F., Morita, K., 2011. An Updated Loop-Mediated Isothermal Amplification Method for Rapid Diagnosis of H5N1 Avian Influenza Viruses. Trop. Med. Health. 39, 3-7.

Drexler, J.F., Helmer, A., Kirberg, H., Reber, U., Panning, M., Muller, M., Hofling, K., Matz, B., Drosten, C., Eis-Hubinger, A.M., 2009. Poor clinical sensitivity of rapid antigen test for influenza A pandemic (H1N1) 2009 Virus. Emerg. Infect. Dis. 15, 1660.5664.

Dunn, J.J., Ginocchio, C.C., 2014. Can newly developed, rapid immunochromatographic antigen detection tests be reliably used for the laboratory diagnosis of influenza virus infections? J. Clin. Microbiol. 53, 1790-1796.

FAO, 2012. H5N1 highly pathogenic avian influenza global overview. April - Jun 2012, No. 32. EMPRES/GLEWS team in FAO. http://www.fao.org/docrep/016/ap387e/ap387e.pdf

Fauci, A.S., Collins, F.S., 2012. Benefits and risks of influenza research: lessons learned. Science. $336,1520.5523$. 
Fu, Y., Callaway, Z., Lum, J., Wang, R., Lin, J., Li, Y., 2014. Exploiting enzyme catalysis in ultra-low ion strength media for impedance biosensing of avian influenza virus using a bare interdigitated electrode. Anal. Chem., 86, 1965-1971.

Goldstein, M.A., Tauraso, N.M., 1970. Effect of formalin, beta-propiolactone, merthiolate, and ultraviolet light upon influenza virus infectivity chicken cell agglutination, hemagglutination, and antigenicity. Appl. Microbiol. 19, 290-294.

Guan, Y., Poon, L.L., Cheung, C.Y., Ellis, T.M., Lim, W., Lipatov, A.S., Chan, K.H., SturmRamirez, K.M., Cheung, C.L., Leung, Y.H., Yuen, K.Y., Webster, R.G., Peiris, J.S., 2004. H5N1 influenza: a protean pandemic threat. Proc. Natl. Acad. Sci. U. S. A. 101, 8156-8161.

Ho, H.T., Qian, H.L., He, F., Meng, T., Szyporta, M., Prabhu, N., Prabakaran, M., Chan, K.P., Kwang, J., 2009. Rapid detection of H5N1 subtype influenza viruses by antigen capture enzyme-linked immunosorbent assay using H5- and N1-specific monoclonal antibodies. Clin. Vaccine. Immunol. 16, 726-732.

Kim, Y.K., Lim, S.I., Cho, Y.Y., Choi, S., Song, J.Y., An, D. J., 2014. Detection of H3N2 canine influenza virus using a Quartz Crystal Microbalance. J. Virol. Methods. 208,16-20.

Leland, D.S., Ginocchio, C.C., 2007. Role of cell culture for virus detection in the age of technology. Clin. Microbiol. Rev. 20, 49-78.

Li, D., Wang, J., Wang, R., Li, Y., Abi-Ghanem, D., Berghman, L., Hargis, B., Lu, H., 2011. A nanobeads amplified QCM immunosensor for the detection of avian influenza virus H5N1. Biosens. Bioelectron. 26, 4146-4154. 
Lin, J., Wang, R., Jiao, P., Li, Y., Li, Y., Liao, M., Yu, Y., Wang, M., 2014. An impedance immunosensor based on low-cost microelectrodes and specific monoclonal antibodies for rapid detection of avian influenza virus H5N1 in chicken swabs. Biosens. Bioelectron. 14, 00724-00726.

Liu, J., Lu, Y., 2006. Preparation of aptamer-linked gold nano- particle purple aggregates for colorimetric sensing of analytes. Nat. Protoc. 1, 246-252.

Lum, J., Wang, R., Hargis, B., Tung, S., Bottje, W., Lu, H., Li, Y. 2015. An impedance aptasensor with microfluidic chips for specific detection of H5N1 avian influenza virus. Sensors 15, 18565-18578.

Lum, J., Wang, R., Lassiter, K., Srinivasan, B., Abi-Ghanem, D., Berghman, L., Hargis, B., Tung, S., Lu, H., Li, Y., 2012. Rapid detection of avian influenza H5N1 virus using impedance measurement of immuno-reaction coupled with RBC amplification. Biosens. Bioelectron. 38, $67-73$.

Ng, E.K., Cheng, P.K., Ng, A.Y., Hoang, T.L., Lim, W.W., 2005. Influenza A H5N1 detection. Emerg. Infect. Dis. 11, 1303-1305.

Postel, A., Letzel, T., Frischmann, S., Grund, C., Beer, M., Harder, T., 2010. Evaluation of two commercial loop-mediated isothermal amplification assays for detection of avian influenza H5 and H7 hemagglutinin genes. J. Vet. Diagn. Invest. 22, 61-66.

Sansyzbay, A.R., Erofeeva, M.K., Khairullin, B.M., Sandybayev, N.T., Kydyrbayev, Z.K., Mamadaliyev, S.M., Kassenov, M.M., Sergeeva, M.V., Romanova, J.R., Krivitskaya, V.Z., Kiselev, O.I., Stukova, M.A., 2013. An inactivated, adjuvanted whole virion clade 2.2 H5N1 
(A/Chicken/Astana/6/05) influenza vaccine is safe and immunogenic in a single dose in humans. Clin. Vaccine Immunol. 20:1314-1319.

Shin, Y.K., Yoon, S.S., Song, J.Y., Kim, J.B., Hang do, T.T., Park, J.W., Kim, M.Y., Kim, S.H., Park, C.K., Li, O.S., 2011. One-step multiplex reverse-transcriptase PCR for detecting pandemic (H1N1) 2009 influenza virus. J. Vet. Med. Sci. 73,55-63.

Su, L.C., Chang, C.M., Tseng, Y.L., Chang, Y.F., Li, Y.C., Chang, Y.S., Chou, C., 2012. Rapid and highly sensitive method for influenza A (H1N1) virus detection. Anal. Chem. 84, 39143920.

Sun, H., Zhu, X., Lu, P.Y., Rosato, R.R., Tan, W., Zu, Y., 2014. Oligonucleotide aptamers: new tools for targeted cancer therapy. Mol. Ther. Nucleic. Acids. 3:e182.

Su, S., Bi, Y., Wong, G., Gray, G.C., Gao, G.F., Li, S., 2015. Epidemiology, Evolution, and Recent Outbreaks of Avian Influenza Virus in China. J. Virol. 89, 8671-8676.

Tanner, W.D., Toth, D.J., Gundlapalli, A.V., 2015. The pandemic potential of avian influenza A(H7N9) virus: a review. Epidemiol. Infect.143, 3359-3374.

Tuerk, C., Gold, L., 1990. Systematic evolution of ligands by exponential enrichment: RNA ligands to bacteriophage T4 DNA polymerase. Science 249, 505-510.

Wang, R., Li, Y., 2013b. Hydrogel based QCM aptasensor for detection of avian influenza virus. Biosens. Bioelectron. 42, 148-155. 
Wang, R., Lin, J., Lassiter, K., Srinivasan, B., Lin, L., Lu, H., Tung, S., Hargis, B., Bottje, W, Berghman, L., Li, Y., 2011. Evaluation study of a portable impedance biosensor for detection of avian influenza virus. J. Virol. Methods. 178, 52-58.

Wang, R., Wang, Y., Lassiter, K., Li, Y., Hargis, B., Tung, S., Berghman, L., Bottje, W., 2009. Interdigitated array microelectrode based impedance immunosensor for detection of avian influenza virus H5N1. Talanta 79,159-164.

Wang, R., Zhao, J., Jiang, T., Kwon, Y. M., Lu, H., Jiao, P., Liao, M., Li, Y., 2013a. Selection and characterization of DNA aptamers for use in detection of avian influenza virus H5N1. J. Virol. Meths. 189, 360.12569.

Webster, R.G., Bean, W.J., Gorman, O.T., Chambers, T.M., Kawaoka, Y., 1992. Evolution and ecology of influenza A viruses. Microbiol. Rev. 56,150.579.

WHO, 2009. Global surveillance during an influenza pandemic. Geneva, Switzerland. http://www.who.int/csr/disease/swineflu/global_pandemic_influenza_surveilance_apr09.pdf

WHO, 2015. Cumulative number of confirmed human cases of avian influenza $\mathrm{A}(\mathrm{H} 5 \mathrm{~N} 1)$ reported to WHO, 2003-2015. October 15, 2015, Geneva, Switzerland. http://www.who.int/influenza/human_animal_interface/EN_GIP_20141223CumulativeNum berH5N1cases.pdf?ua=1

WHO, 2007. Phylogenetic tree from Evolution Working Group poster. Geneva, Switzerland. http://www.who.int/entity/influenza/gisrs_laboratory/tree_large.pdf?ua=1 
WHO, 2014. WHO information for molecular diagnosis of influenza virus. Geneva, Switzerland. http://www.who.int/influenza/gisrs_laboratory/molecular_diagnosis_influenza_virus_human s_update_201403.pdf?ua=1

Xu, J., Suarez, D., Gottfried, D.S., 2007. Detection of avian influenza virus using an interferometric biosensor. Anal. Bioanal. Chem. 389, 1193-1199.

Xu, L., Wang, R., Kelso, L. C., Ying, Y., Li, L., 2016. A target-responsive and size-dependent hydrogel aptasensor embedded with QD fluorescent reporters for rapid detection of avian influenza virus H5N1. Sensor. Actuat. B-Chem. 234, 98-108.

Yang, L., Li, Y., Erf, G.F., 2004. Interdigitated Array microelectrode-based electrochemical impedance immunosensor for detection of Escherichia coli O157:H7. Anal. Chem. 76, 11071113.

Zheng, J., Feng, W., Lin, L., Zhang, F., Cheng, G., He, P., Fang, Y., 2007. A new amplification strategy for ultrasensitive electrochemical aptasensor with network-like thiocyanuric acid/gold nanoparticles. Biosens. Bioelectron. 23, 341-347. 


\section{Figure captions:}

Fig. 1. Schematic representation of the microelectrode based impedance assay for detection of avian influenza virus H5N1. (1) Bare microelectrode; (2) Streptavidin was immobilized on the surface of microelectrode; (3) Biotinylated H5N1 aptamers were bound to the immobilized streptavidin on the microelectrode; (4) The electrode surface was blocked with the polyethylene glycol; (5) H5N1 viruses were bound to the aptamers; and (6) The amplifiers with gold nanoparticles were bound to the captured H5N1 viruses.

Fig. 2. Impedance magnitude response at the frequency $100 \mathrm{~Hz}$ after microelectrode modification with streptavidin, aptamer, PEG, and H5N1 sample (30 $\mu \mathrm{l}$ of $0.25 \mathrm{HAU} / 50 \mu \mathrm{l})$. Amplitude of voltage, $10 \mathrm{mV}$. The star denotes $p$ value $<0.05$. The means and error bars were calculated based on 3 replicates. Measuring solution was the $10 \mathrm{mM}[\mathrm{Fe}(\mathrm{CN}) 6] 3-/ 4-(1: 1)$ mixture redox probe in PBS (pH 7.4).

Fig. 3. The impedance magnitude (A) and phase angle (B) of bare microelectrode, streptavidin, aptamer, PEG, H5N1sample (30 $\mu \mathrm{l}$ of $0.25 \mathrm{HAU} / 50 \mu \mathrm{l})$ incubation and labeling with amplifiers in the frequency range from $10 \mathrm{~Hz}$ to $1 \mathrm{MHz}$. Amplitude of voltage, $10 \mathrm{mV}$. Measuring solution was the $10 \mathrm{mM}[\mathrm{Fe}(\mathrm{CN}) 6] 3-/ 4-(1: 1)$ mixture redox probe in $\mathrm{PBS}(\mathrm{pH} 7.4)$.

Fig. 4. (A) An equivalent circuit used for data analysis. The equivalent circuit components were electron transfer resistor $\left(R_{\mathrm{et}}\right)$, double layer capacitance $\left(C_{\mathrm{dI}}\right)$, the resistance of the solution $\left(R_{\mathrm{S}}\right)$, and Warburg impedance $\left(W_{\mathrm{z}}\right)$. (B) A Bode diagram of measured impedance data and simulated impedance data generated by curve fitting of the equivalent circuit. The measured data are from the test with samples containing 0.25 HAU H5N1 virus.

Fig. 5. Impedance changes of the microelectrodes at a frequency of $100 \mathrm{~Hz}$ recorded by the aptasensing system for different concentrations of the target H5N1 virus including a logarithmic 
regression line. The means and error bars were calculated based on 3 replicates. Measuring solution was the $10 \mathrm{mM}[\mathrm{Fe}(\mathrm{CN}) 6] 3-/ 4-(1: 1)$ mixture redox probe in PBS (pH 7.4).

Fig. 6. Change in impedance magnitude between the targets H5N1 virus, non-target influenza virus, and negative control sample treatments at $100 \mathrm{~Hz}$ frequency. The concentration of H5N1 subtypes was $16 \mathrm{HAU}$. The means and error bars were calculated based on 3 replicates. Measuring solution was the redox probe solution.

Fig. 7. Conventional RT-PCR amplification of influenza virus H5N1 matrix gene. Shown in an ethidium-bromide-stained $2 \%$ agarose gel loaded with a 50-bp ladder. Amplicon size is $244 \mathrm{bp}$.

Fig. 8. (A) Real-time RT-PCR for detection of difffent titers of influenza virus H5N1, 16 to 0.125 HAU. The Ct (cycle threshold) was defined as the number of cycles required for the fluorescent signal to cross the threshold value. The samples with $C t$ values of less than 30 were considered positive. (B) Correlation between the reading of impedance change from the aptasensor and the reading of $\mathrm{Ct}$ value from $\mathrm{rRT}-\mathrm{PCR}$. 
Fig. 1.

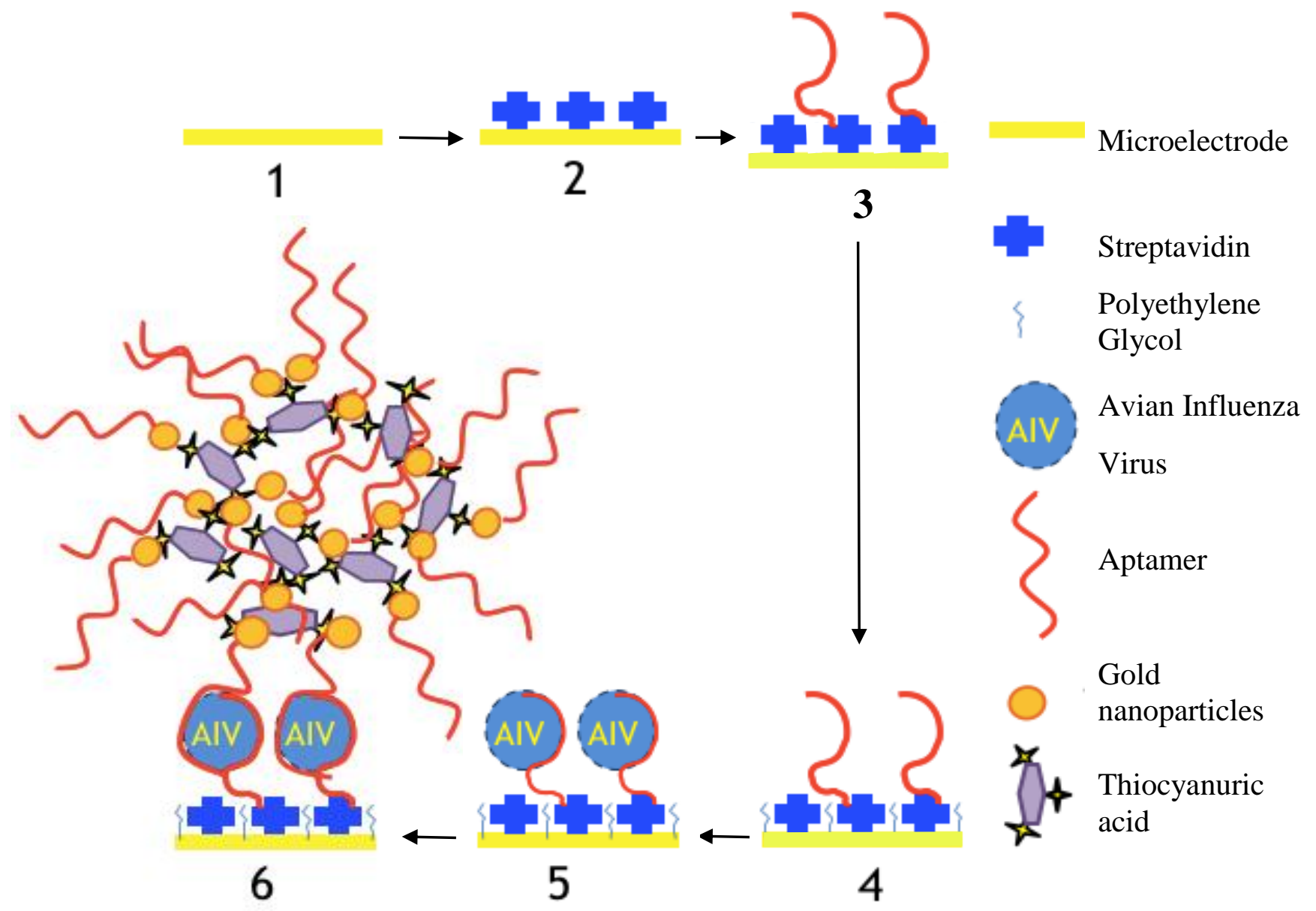


Fig. 2.

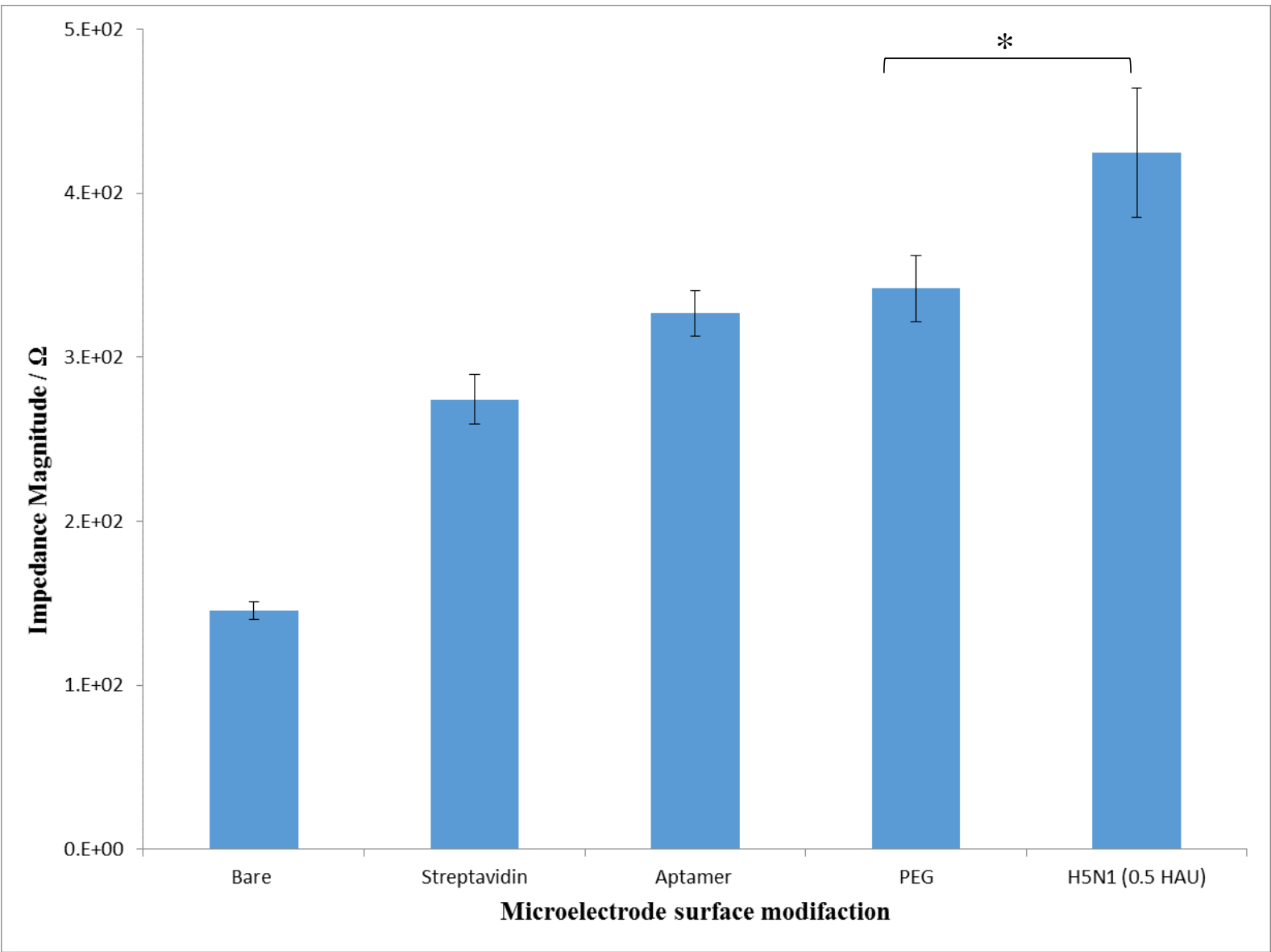


Fig. 3.(A)

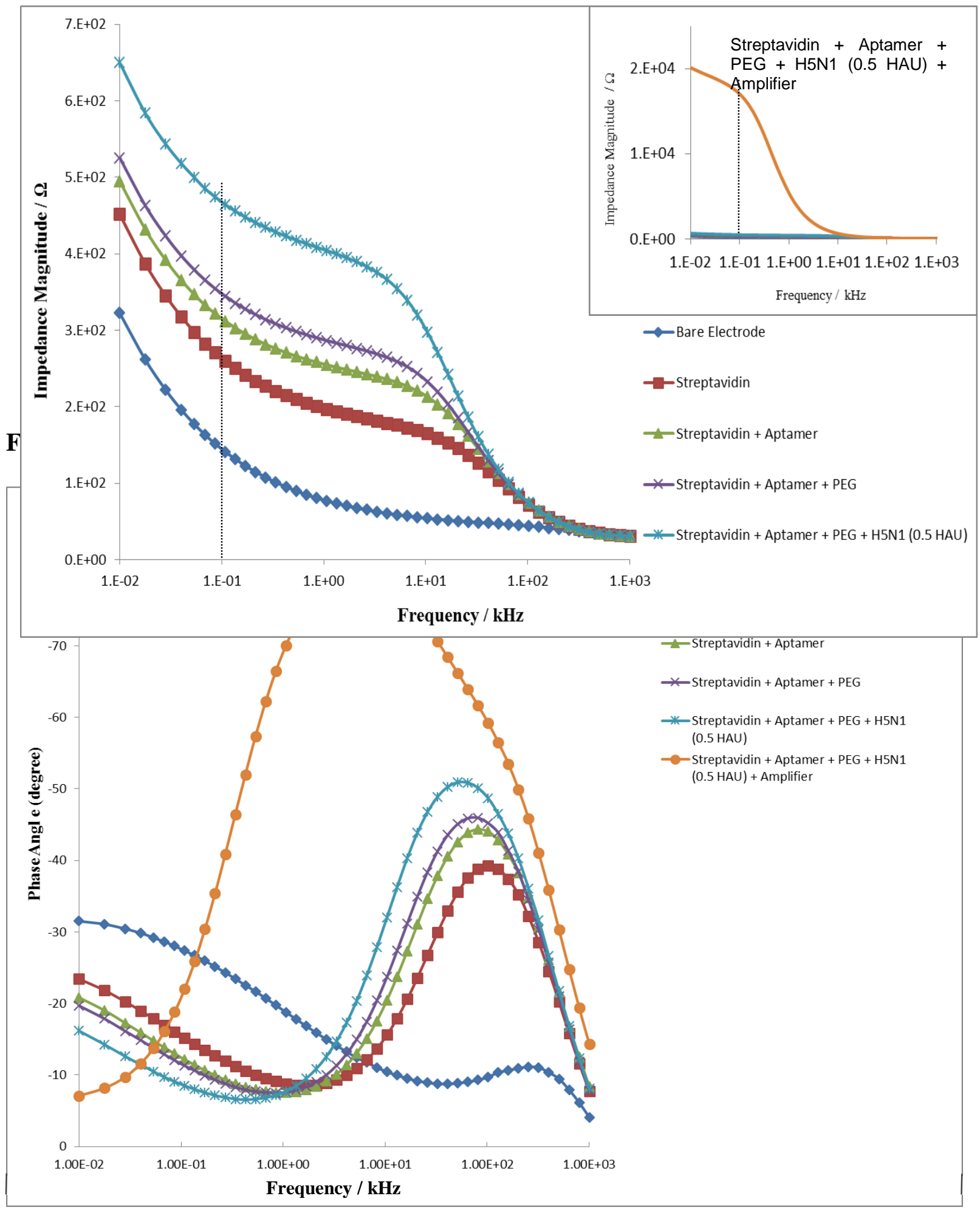


Fig. 4. (A)

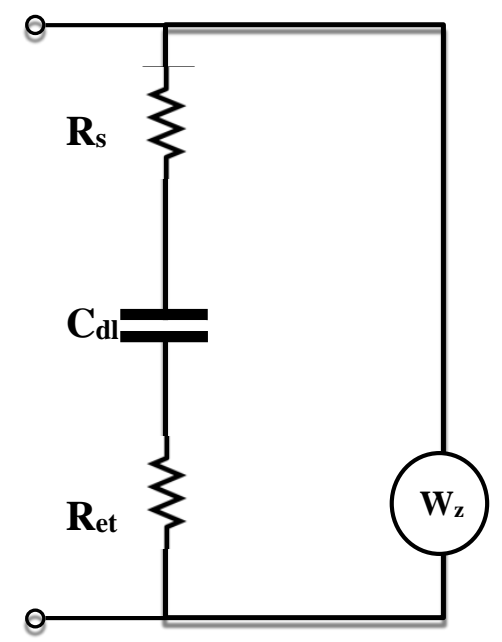

(A)

(B)

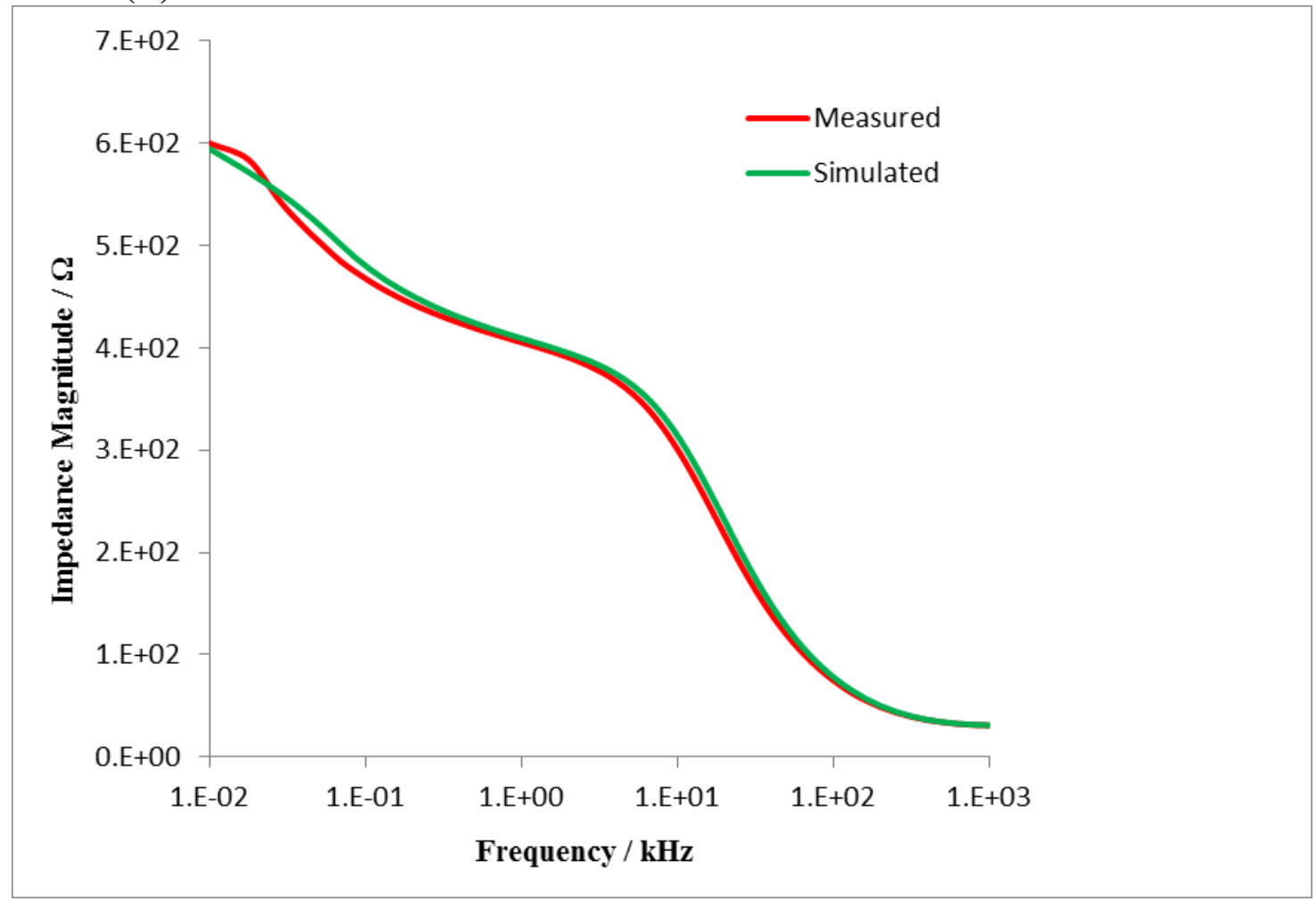


Fig. 5.

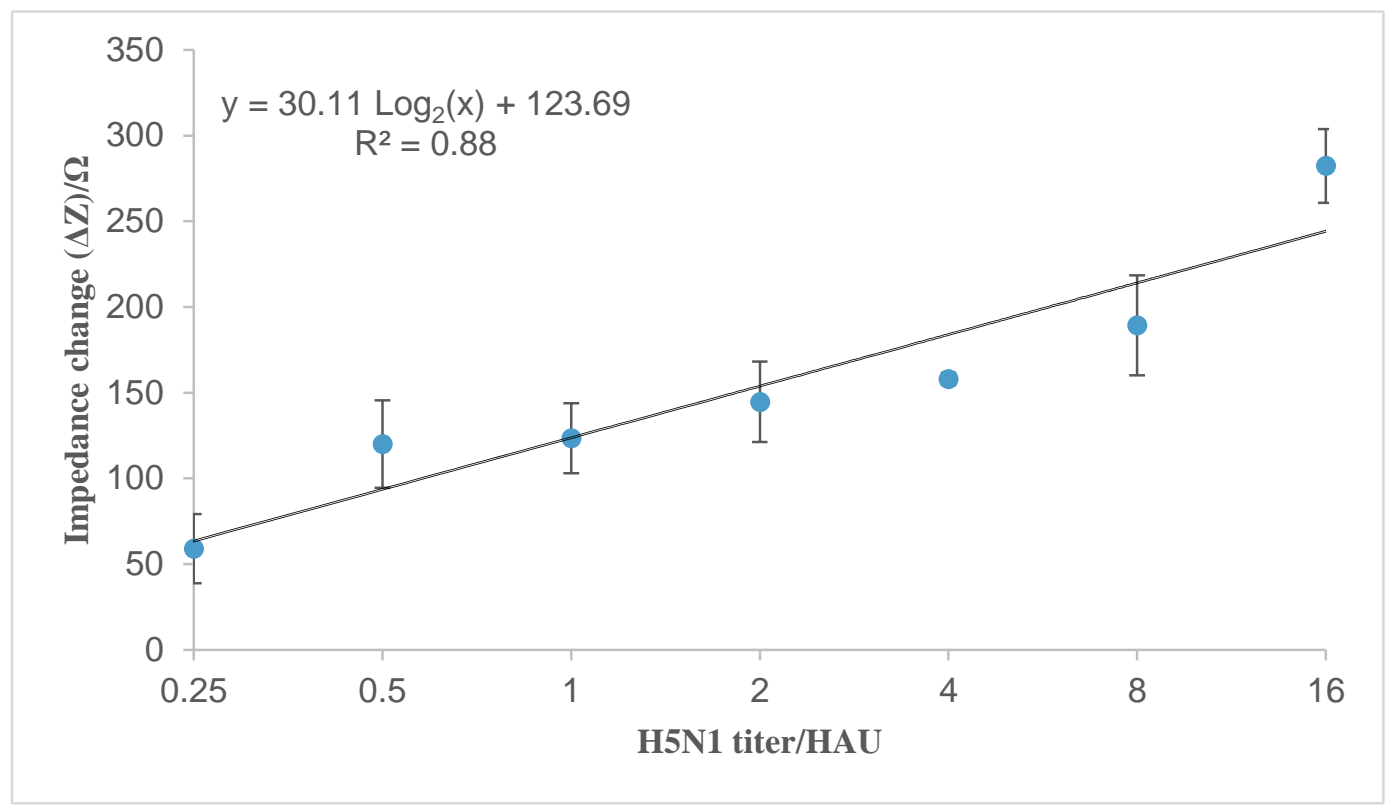

Fig. 6.

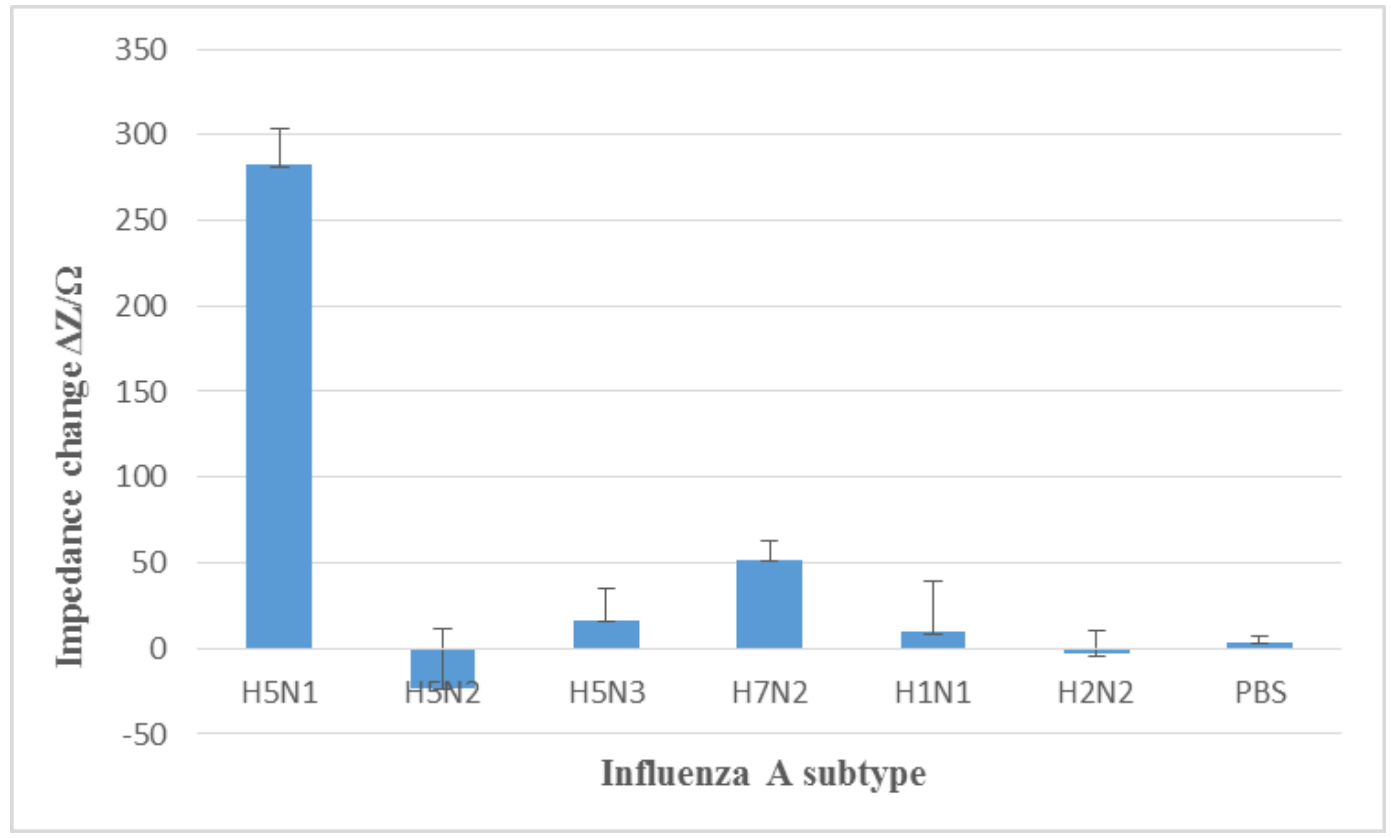


Fig. 7.

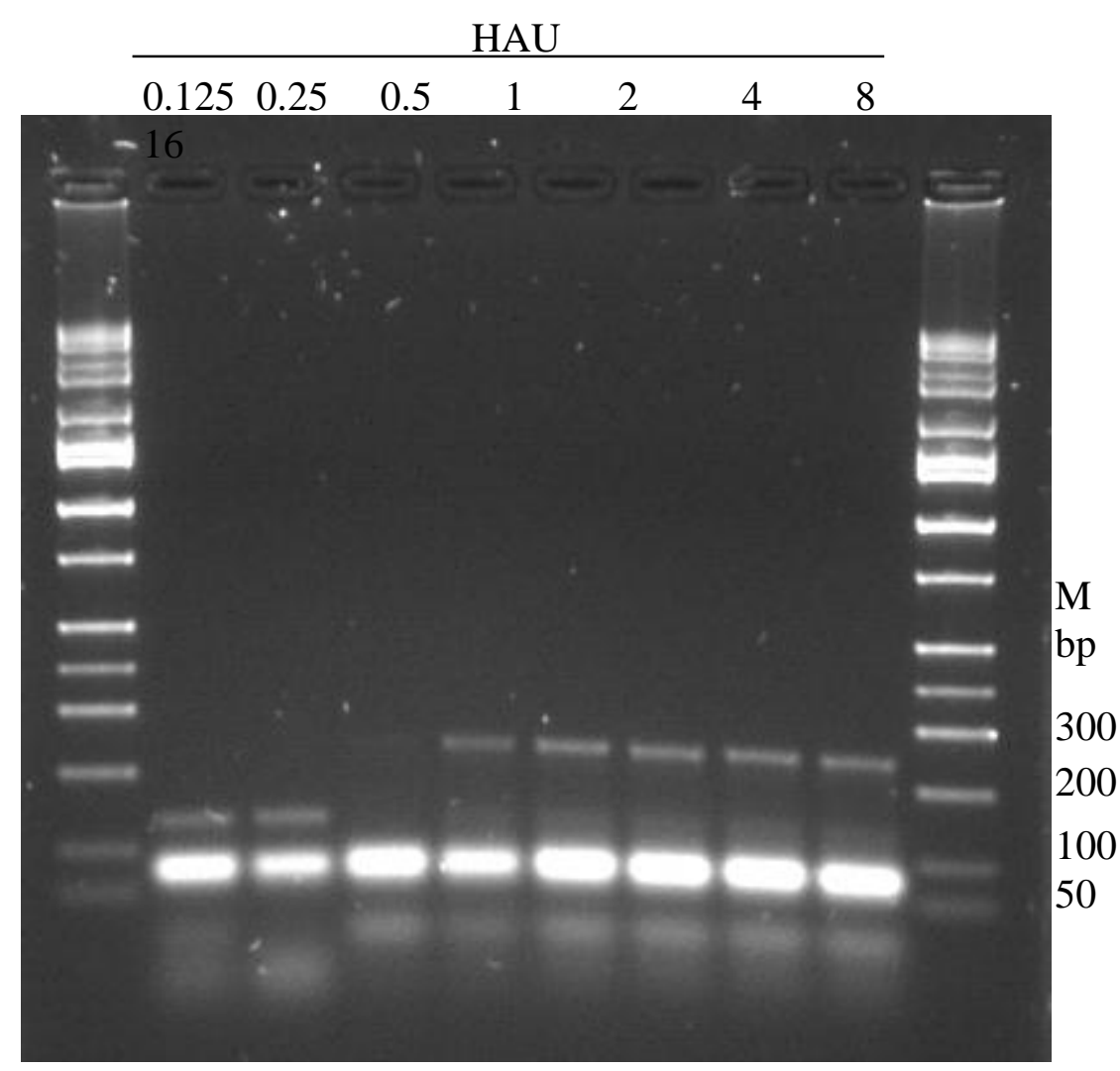


Fig. 8. (A)

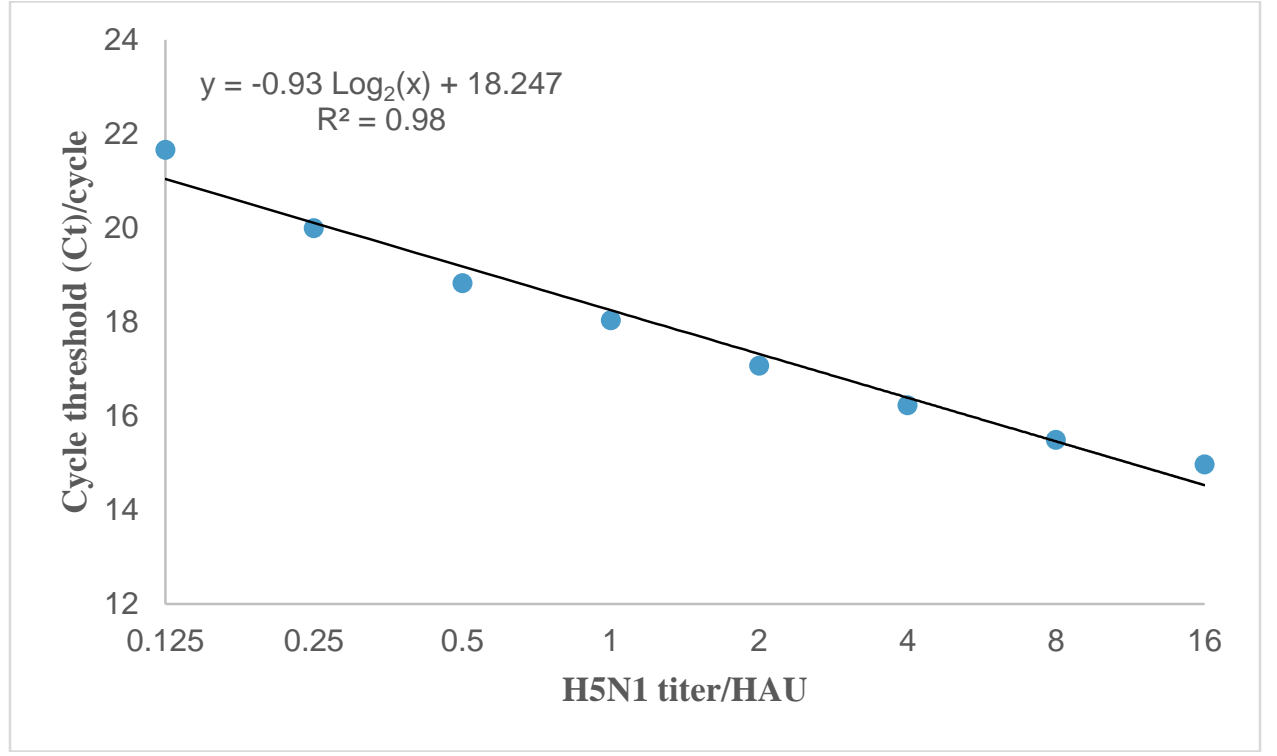

(B)

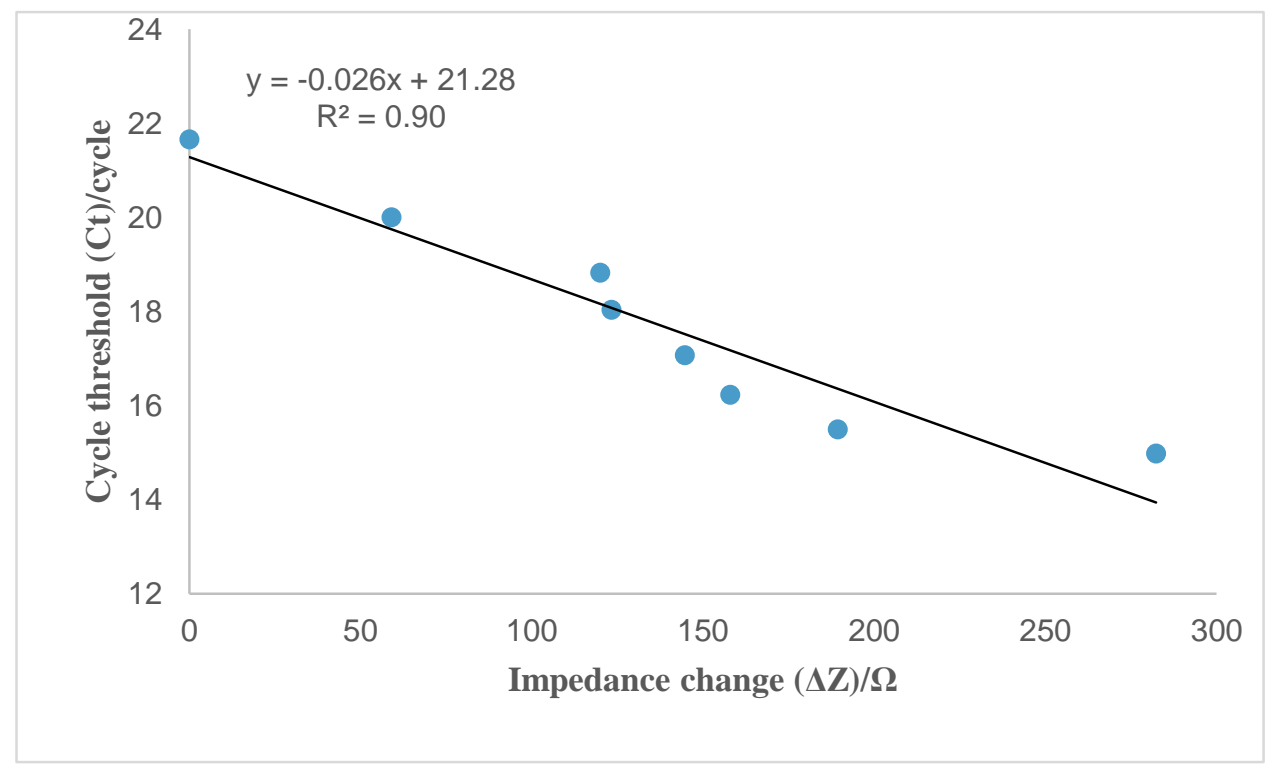


Table 1. Impedance signal amplification for pure virus and spiked chicken swab samples

\begin{tabular}{|c|c|c|c|}
\hline \multicolumn{4}{|c|}{ Pure H5N1 virus } \\
\hline HAU & $\Delta \mathrm{Z}$ of H5N1 without amplifier ${ }^{\mathrm{a}} \pm \mathrm{SD}$ & $\Delta \mathrm{Z}$ of $\mathrm{H} 5 \mathrm{~N} 1$ with Amplifier ${ }^{\mathrm{b}} \pm \mathrm{SD}$ & $\Delta \mathrm{Z}$ fold increase $\mathrm{c}^{\mathrm{c}}$ \\
\hline 2 & $145 \pm 2$ & $20156 \pm 1667$ & 116 \\
\hline 1 & $123 \pm 20$ & $9137 \pm 3826$ & 47 \\
\hline 0.5 & $120 \pm 26$ & $14907 \pm 1688$ & 96 \\
\hline 0.25 & $59 \pm 20$ & $12283 \pm 455$ & 152 \\
\hline 0.125 & $0 \pm 3$ & $5331 \pm 1516$ & \\
\hline PBS & $4 \pm 3$ & $3250 \pm 919$ & \\
\hline
\end{tabular}

\section{Chicken swab samples spiked with pure virus}

\begin{tabular}{lccc}
\hline HAU & $\Delta Z$ of H5N1 without amplifier ${ }^{\mathrm{a}} \pm \mathrm{SD}$ & $\Delta \mathrm{Z}$ of H5N1 with Amplifier ${ }^{\mathrm{b}} \pm \mathrm{SD}$ & $\Delta \mathrm{Z}$ fold increase \\
\hline 2 & $143 \pm 62$ & $23374 \pm 5853$ & 139 \\
\hline 1 & $134 \pm 55$ & $13372 \pm 5020$ & 57 \\
\hline 0.5 & $116 \pm 28$ & $11767 \pm 1343$ & 72 \\
\hline 0.25 & $113 \pm 13$ & $8827 \pm 616$ & 48 \\
\hline Swab & $11 \pm 40$ & $3318 \pm 230$ &
\end{tabular}

Impedance changes of the microelectrodes at frequency $100 \mathrm{~Hz}$ recorded by the aptasensing system for different concentrations of the target pure H5N1 virus and chicken swab samples spiked with pure H5N1 virus. The impedance changes were recorded for the tested viruses without amplifier and with amplifier. Mean and SD were based on three replicates. ${ }^{a} \Delta \mathrm{Z}$ (impedance change/ $\Omega$ ) was calculated by subtracting H5N1 impedance from complex impedance (bare, streptavidin, aptamer, and PEG). ${ }^{\mathrm{b}}$ was calculated by addition the complex, H5N1, and amplifier impedance. ${ }^{c} \Delta Z$ fold increase $=(\Delta Z$ of H5N1 with Amplifier $-\Delta Z$ of PBS (3250)) / $\left(\Delta \mathrm{Z}\right.$ of H5N1 without amplifier), ${ }^{\mathrm{d}} \Delta \mathrm{Z}$ fold increase $=(\Delta \mathrm{Z}$ of H5N1 with Amplifier $-\Delta \mathrm{Z}$ of swab (3318)) / ( $\Delta \mathrm{Z}$ of H5N1 without amplifier). 